\title{
Píldoras para salvar la Constitución de 1991 (II parte) Procesos de constitucionalización en el Imperio del Hiperpresidencialismo
}

\author{
Fernando Aurelio Guerrero Cárdenas \\ Abogado, Magíster en Litigio Internacional en DDDHH y DIH, Universidad Santo Tomás-Bogotá (Colombia) \\ Especialista en Derecho Administrativo, Universidad Santo Tomás-Bucaramanga (Colombia) \\ Especialista en Derecho Constitucional, Universidad Santo Tomás-Bucaramanga (Colombia) \\ E-mail: fernandoguerreroc@hotmail.com
}

\begin{abstract}
Resumen
No parece raro un estudio sobre constitucionalización del derecho, pero sí sobre la constitucionalización de deseos del ejecutivo en escenarios de hiperpresidencialismo. En un estudio anterior se intentó reflejar como el activismo del ejecutivo acaudillaba el constituyente derivado e incluso reflejaba intromisión en el control del representante argumentativo, y como sólo el ejercicio de un derecho fundamental parece ser el que ha intentado enfrentar dicho fenómeno. En este escrito se describirá el caso más emblemático y ejemplar que evidencia la constitucionalización de actos legislativos hiperpresidencialistas, no sin antes aprovechar para reflexionar sobre ¿qué se entiende por constitucionalización? y posteriormente estudiar algunos casos de control convencional a temas constitucionales.
\end{abstract}

Palabras Clave: Constitucionalización, Sustitución de la Constitución, Democracia, Hiperpresidencialismo.

\begin{abstract}
It seems odd a study of constitutionalization of the law, but about the constitutionalization of executive wishes hyper scenarios. In a previous study we tried to reflect as executive activism acaudillaba derived constituent and even reflected interference in controlling argumentative representative, and as only the exercise of a fundamental right appears to be that the process has faced. In this paper, we describe the most emblematic and exemplary evidence constitutionalise hiperpresidencialistas legislation, but first pause to reflect on what is meant by a constitution? And then study some cases executive hiperactivismo in conventional control headquarters.
\end{abstract}

Keywords: Constitutionalisation, Replacing the Constitution, Democracy, Presidentialism.

\section{Riassunto}

Sembra strano uno studio di costituzionalizzazione del diritto, ma circa la costituzionalizzazione del dirigente augura scenari iper. In uno studio precedente abbiamo cercato di riflettere come esecutivo attivismo acaudillaba costituente derivato e anche riflettuto interferenze nel controllo rappresentativo polemico, e come solo l'esercizio di un diritto fondamentale sembra essere che il processo ha dovuto affrontare. In questo articolo, descriviamo le prove costituzionalizzazione legislazione hiperpresidencialistas più emblematico ed esemplare, ma prima pausa per riflettere su cosa si intende per una costituzione? e poi studiare un po 'di casi hiperactivismo esecutivo in sede di controllo convenzionale.

Parole Chiave: Costituzionalizzazione, Sostituendo la Costituzione, la Democrazia, il Presidenzialismo. 



\title{
Píldoras para salvar la Constitución de 1991 (II Parte) procesos de constitucionalización en el Imperio del Hiperpresidencialismo*
}

\section{CONSTITUCIONALIZACIÓN A SECAS: DE QUIÉN, DE QUÉ, CÓMO, DÓNDE, PARA QUÉ}

\author{
"Hay juristas divididos en dos bandos... \\ los que van tras el noble sueño... y los que defienden la pesadilla” Hart.
}

El diálogo sobre lo que se entiende por constitucionalización, es uno de los más abordados dentro del estudio del derecho, ya sea para negarlo, intentar vincularlo a alguna teoría, o para defender por ejemplo sus efectos, produciéndose así diferentes posturas, puntos de partida, o la inclusión o exclusión de alguna dimensión, las cuales pueden basarse en tesis que se direccionan hacia fines que se contradicen entre unos y otros, o que se basan en hipótesis, factores y supuestos distintos, algunos incluyendo transplantes de teorías de internacionalistas destacados y otros en una embrionaria construcción local. Puede decirse que es un fenómeno con varias décadas de estudio pero todavía ambiguo y hasta algo difuso, que en definitiva, a pesar de ser abordado en un buen número de textos, merece ser revaluado, especialmente si se quiere abordarlo como problema del derecho y de una dogmática local.

\subsection{Una exploración necesaria}

Punto de partida. Preguntas al profesor Juan Jacobo. Un buen punto de partida doméstico que traza una ruta de diálogo desde lo local para una teoría local, se encuentra en los estudios del profesor Juan Jacobo Calderón (2005, 2007 y 2011), en ellos enfrentó el desafío de abordar la constitucionalización como problema, antes de pasar a su principal interés que es la constitucionalización del derecho privado, muestra de ello se refleja especialmente en el estudio que realizó junto con la Dra. Nelcy López y el profesor Erick Rincón Cárdenas (2005). Se preguntó

* El presente escrito se realiza desde las investigaciones desarrolladas para la Segunda Vicepresidencia del Senado de la República de Colombia del 2011-2012 en relación a la necesidad de estudiar el fenómeno de la Doctrina de la Sustitución de la Constitución proporcionada por la Corte Constitucional y el seguimiento en ese sentido al VII Encuentro de la Corte Constitucional del 2011. 
si se podría considerar la constitucionalización del derecho como problema de investigación ${ }^{1}$ y describir los distintos sentidos en los que puede emplearse la palabra constitucionalización ${ }^{2}$, desafiando lo ya dicho por internacionalistas destacados y cuestionando lo que para otros es ya una obviedad e incluso repetitivo estudiar ${ }^{3}$.

En su estudio posterior independiente, el profesor Juan Jacobo ${ }^{4}$ concentra la atención en resaltar la dependencia de la constitucionalización a ciertos factores como un activismo judicial de la Corte Constitucional, la densidad y precisión de regulación constitucional, o el grado de simetría de las relaciones donde se involucran derechos

1 A nivel internacional quien ha encontrado la constitucionalización también como problema propio de investigación es el profesor Louis Favoreau (1996) al preocuparse por su noción terminológica, y rastreando sus orígenes que datan de 1939 con Mrcel Waline y J. Belin, y el debate entre Vedel y Charles Eisenmann, con escritos y respuestas de 1949, 1954 y 1989 con Vedel y de 1957 y 1972 con Eisenmann. Incluyendo como problema la manera de describir el proceso de constitucionalización articulado por la generalización de la aplicación de la Constitución que pasa por analizar el "hiperconstitucionalismo", el "panconstitucionalismo", el "todo constitucional"y otras desviaciones. También advierte el proceso de constitucionalización sobre la imagen de una normatividad en cascada, que haría emanar toda solución de la Constitución por grados sucesivospercibida desde una lógica desencarnada, e identificada con el mecanismo que permitió la instalación de regímenes totalitarios. Igualmente señala que existen efectos directos e indirectos de la constitucionalización, de los primeros salen tres tipos de constitucionalización: La constitucionalización-juridización, la constitucionalización-elevación, la constitucionalización-transformación, de los indirectos está la constitucionalización del derecho y la constitucionalización del orden jurídico.

2 La ontología, axiológica y epistemología de la constitucionalización, en las investigaciones se aborda como un fenómeno concretizado o como una categoría que depende de lo ya dicho por una "escuela jurídica global". Su estudio es residual en la dogmática jurídica y teoría local, su categorización doméstica se encuentra en etapa embrionaria.

3 Textos como los de Prieto Sanchís, Josep Aguiló (2008) o Paolo Comanducci (2010), entre otros, parten de lo descrito por Guastini (sobre las principales condiciones de constitucionalización, a las cuales se adscriben de manera completa casi todos, como en Constitucionalización y neoconstitucionalismo, por así: 1.La existencia de una constitución rígida que incorpore los derechos fundamentales. 2. La garantía de la Constitución. 3. La fuerza vinculante de la Constitución (que no es un conjunto de normas programáticas sino preceptivas). 4. La sobre interpretación de la Constitución (se le interpreta extensivamente y de ella se deducen principios implícitos). 5. La aplicación directa de las normas constitucionales, también en las relaciones entre particulares. 6 . La interpretación adecuada de las leyes. 7. La influencia de la Constitución sobre el debate político.

4 En entrevista realizada en la Universidad Santo Tomás, Juan Jacobo Calderón, al abordar las condiciones que presuponen la existencia de un proceso de constitucionalización en un ordenamiento jurídico, precisó que está se debe presentar en dos niveles, uno que relacione las condiciones generales (presupuestos globales de existencia) y otro las condiciones particulares (modos de constitucionalización local). Respecto de las condiciones generales, presentó cuatro formulaciones bicondicionales, según su tesis un ordenamiento puede ser constitucionalizado si y sólo si la Constitución es una norma jurídica y esa norma jurídica es norma superior, si y sólo si existen órganos para asegurar que esa norma sea respetada como la norma que define la validez del resto del ordenamiento, si y solo si existen procedimientos que aseguren la integridad y supremacía de la Constitución, y, si y solo si se trate de una Constitución rígida que presente algunos procedimientos especiales para su modificación. Respecto a los modos de Constitucionalización, precisó que dependen si se surten por vía judicial o por vía legislativa, de si su objeto es material, dogmático, de derechos fundamentales u orgánico formal. Concluye que de manera tal, las constitucionalizaciones no siempre son de Estados Democráticos, pueden ser constitucionalizaciones de Estados absolutistas que producen una constitucionalización autoritaria. Link del video http://www.youtube.com/watch? $\mathrm{v}=\mathrm{Bj} 58 \mathrm{EkkkVpE}$ 
fundamentales. Concluyó que la importancia de la constitucionalización se encuentra en razón a sus efectos, los cuales principalmente han forzado la recomposición del sistema de fuentes, generando una nueva actitud no sólo hacia la Constitución sino hacia la jurisprudencia de la Corte Constitucional, los Tratados Internacionales de Derechos Humanos y las Sentencias de las Cortes Internacionales de Derechos Humanos, y además, han reincorporado nuevas metodologías de interpretación para resolver casos, activado nuevas formas de litigio, y han gestado un encuentro entre las formas de razonamiento jurídico especialmente sobre lo que es derecho público y derecho privado.

El valor de abordar eso de ¿qué se entiende por constitucionalización? para una construcción de sus premisas desde la dogmática y la teórica local en un Estado de singular ejemplo mundial, no puede más que festejarse presentando preguntas de reflexión sobre el problema de la definición de la constitucionalización, que de hecho sigue presentando serias dificultades si se mira con mayor abstracción o con mayor especificidad, sobre todo cuando se busca el equilibrio de una constitucionalización local adecuada, y la comprensión de la constitucionalización como categoría global e independiente que se ocupe de lo que se ha dicho y se pregunte por distinguirlo de ideologías, doctrinas y teorías 5 .

Primero una aproximacióndesde Comanducci (2010), sin duda el más citado cuando se abordan los problemas de la constitucionalización, es el trabajo del Decano de la Facultad de Derecho de la Universidad de Génova (Italia), al que incluso también se le atribuye, junto con tres de sus hermanos de escuela el bautizo de la nueva doctrina del derecho, a la que llamaron en los 90's "Neoconstitucionalismo". Para el profesor el cambio en el ámbito jurídico de las últimas décadas, es estructural y doctrinal, por un lado el cambio estructuralse debe a la "constitucionalización" del Derecho, y el cambio doctrinalal "neoconstitucionalismo", sin embargo, considera necesario abordar el estudio de los mismos relacionándolos entre sí, "ya que uno favorece y sustenta al otro en un proceso de acción y retroacción" (Comanducci, 2010), sin embargo no niega que el estudio se puedas hacer de manera independiente (Comanducci, Ahumada y González, 2009), adicionalmente advierte que se concentra más en presentar al neoconstitucionalismo pero sindejar de enunciar la constitucionalización, conforme a su tesis de acción y retroacción, describiéndola en las formas homogéneas en que se presenta la doctrina del neoconstitucionalismo.

Debe decirse en primer lugar que el profesor Comanducci (2010) al colocar la

5 Por ejemplo, si se quiere se puede resolver los problemas de la constitucionalización desde sus relaciones con el positivismo, constitucionalismo y neoconstitucionalismo, los cuales incluso tienen individualmente problemas propios. Hablar de constitucionalización debería suponer hacer referencia a cuestiones que no necesariamente respondan a un neoconstitucionalismo(s), constitucionalismo(s) o positivismo(s), e incluso algún iusnaturalismo(s), deberían estudiarse por separado, incluso de los fenómenos evolutivos que han tenido evidentes impactos en lo que se ha llamado nuevo paradigma, como el Estado constitucional, operatividad constitucional, o justiciabilidad de los derechos fundamentales. 
"constitucionalización" dentro de los tipos de neoconstitucionalismo, lo acoge junto a su objeto al que se dirige, es decir, el Derecho, no lo presenta sin apellido y también que parte del suponer que se trata de un proceso, es decir lo trata como el proceso de la constitucionalización del derecho.

Al exponer los tres tipos "homogéneos" de neoconstitucionalismo, Comanducci (2010)señala que los efectos positivos de la constitucionalización intentan ser descritos por el neoconstitucionalismo como teoría del Derecho, las exaltaciones y valoraciones a esos logros del proceso de constitucionalización son defendidos y ampliados por el neoconstitucionalismo ideológico, y los estudios de los sistemas constitucionalizados presuponen una toma de posición necesaria frente al derecho que debe ser a través de un neoconstitucionalismo metodológico.

La particular distinción del profesor Paolo, contribuye a justificar muchos de los trabajos futuros sobre la constitucionalización y el neoconstitucionalismo, sin embargo la dimensión superior de la constitucionalización no expuesta por Comanducci (2010) ha sido poco explorada. Una ampliación de dicho estudio puede justificarse con una razón teórica y una fáctica. En primer lugar, porque no se niega que la constitucionalización pueda ser tratada como categoría propia y presentar problemas singulares, ni tampoco que deba estar ligada a una teoría o una doctrina en particular. En segundo lugar, porque no es fácilmente rastreable, mucho menos en el escenario local, un estudio sobre la constitucionalización como categoría propia e independiente que intente razonar sobre sus presupuestos desde los sujetos y objetos. A continuación se presentará tan solo unas reflexiones sobre esta postura.

La concepción de la constitucionalización. Para intentar justificar el estudio adicionalmente podrían plantearse las siguientes preguntas a modo de reflexión previa: ¿Cómo surge una constitucionalización? ¿Sí se puede concebir una constitucionalización sin una Constitución? ¿Una constitucionalización comporta un concepto de Constitución? Bueno, a la primera pregunta podrían surgirle respuestas desde un enfoque histórico, jurídico, o práctico, entre otras; la segunda podría estar relacionada con la tercera y llevaría a preguntarse primero ¿qué se entiende por Constitución?-postura de por sí problemática- (Kenneth, 1971) Schimitt, 1982; Laporta, 2004; Uprimni, 2007).

Esto indica que la constitucionalización es una categoría de abstracción y especificidad amplia y su estudio es válido, por ejemplo para un enfoque historicista metodológico podría decirse que una Constitución material existe antes de una Constitución formal, por tanto que unos valores pre políticos serían parte esencial de esa Constitución, o que incluso, se puede decir que prexistió algún tipo de proceso de constitucionalización antes de la promulgación del texto como norma superior; para una teoría de la constitucionalización puede escogerse un concepto de Constitución garantista (Ferrajoli, 2001) que acepte el derecho como un sistema de garantías en estado de crisis de la razón jurídica, por tanto, se acepta la doble dimensión artificial del ordenamiento jurídico respecto a la producción de la Constitución, una formal y una material, lo cual implica desarrollos descriptivos respecto a su "ser" y 
desarrollos axiológicos respecto a su "deber ser", aceptando una concepción de un Estado constitucional de derecho, que condiciona y orienten la acción estatal desde vínculos jurídicos formales y sustanciales ${ }^{6}$.

\subsection{Puntos de apoyo para un estudio en serio}

Constitucionalización sin padres adoptivos: para realizar las debidas distinciones en la especificidad problemática del estudio de la constitucionalización, se podría reflexionar sobre si ¿la constitucionalización podría estudiar sedes ligándola de una teoría del derecho e incluso de una especie de constitucionalismo? Esto para abordarlo como categórica independiente que distinga sus posibles dimensiones, con problemas en cada una de ellas. Si esto se acepta, podría abordarse la constitucionalización por ejemplo en tres círculos, uno a modo de "laberinto epistemológico", otro de "recipiente" y otro de panóptico "ético", cada uno afrontaría problemas propios e independientes relacionados con la epistemología, la lógica, la teoría y la deontología?, y aceptaría distintas formas de presentarse la constitucionalización ${ }^{8}$.

Modos de Constitucionalización y Constitución. Por otra parte, podrían surgir diferentes posturas que surgirían de la relación entre los modelos de constitucionalización y el concepto de constitución que se adopte, por ejemplo, una de las dimensiones podría asumir una visión formalista dela Constitución o podría preferir una visión operativa para los Estados Constitucionales, la otra dimensión podría preferir describir la Constitución o resaltar la realidad dinámica de la Constitución, y en otra dimensión podrían surgir interpretaciones de la Constitución axiológica o interpretaciones que prefieran los criterios formales o procedimentales sin importar si son casos de "anormalidad". Del mismo modo, pueden presentarse posturas que aceptan por una lado una dimensión realista pero que en la otra dimensión no acepta un carácter abierto e indeterminado de la Constitución, o una dimensión que admite como importante vincular como objeto a constitucionalizar criterios políticos, económicos o morales pero que no admite en otra dimensión que la Constitución permita juicios de control material a las reformas.

Constitucionalización con apellido. Otra pregunta por reflexionar tiene que ver

$6 \quad$ El aceptar el estado de crisis, se incluye por lo menos según Ferrajoli (2001), el aceptar que existe alguna evidencia de ausencia o ineficacia de legalidad, esto relacionado al control constitucional a reformas constitucionales, permite justificar la pérdida de confianza en la razón jurídica e imponer cargas de racionalidad formal y sustancial a la representación argumentativa. Al respecto ver Racionalidad formal y racionalidad sustancial en el paradigma garantista de la validez, de Ferrajoli, L. (2001). Un estudio juicioso sobre el tema del Dr. Suárez (2011).

7 Rafael Escudero Alday en Guía para realistas analíticos (2010) identificó en Paolo Comanducci (2010) la delimitación de los diferentes problemas del teórico del derecho italiano en cuatro tipos de problemas abiertos: epistemológicos, lógicos, teóricos y deontológicos.

8 El texto de Riccardo Guastini, Distinguiendo. Estudios de metateoría y teoría del derecho, podría servir para ampliar las maneras de como aborda la especificidad del problema de la constitucionalización, su tesis propone una fórmula general expuesta primero en Norberto Bobbio (2004), El problema del positivismo Jurídico. 
conel objeto relacional, es decir, si se acepta que un estudio de la constitucionalización también dependa de que tanto se acepta su relación con el derecho, con la economía, con la sociedad, con la cultura, con la política, etc., así las cosas, podría aceptarse el estudio por ejemplo de la constitucionalización del derecho internacional, de la constitucionalización de análisis económicos ${ }^{9}$, o de la constitucionalización de sociedades contemporáneas, etc.

Si se acepta otros tipos de constitucionalizaciones pero se escoge por ejemplo profundizar la relación constitucionalización y Derecho, surgen también diferentes posturas teóricas, las cuales dependen, en principio, del concepto de Derecho que se tenga y de lo que se quiera entender del Derecho, lo cual supone a su vez diferentes respuestas y así mismo varias tipologías, lo eventual es que una postura sobre la constitucionalización del derecho en conjunto, necesariamente debe tomar posición sobre los problemas acerca de ¿qué es el derecho?

Del mismo modo una postura sobre la constitucionalización del derecho debe responder sobre el concepto del objeto involucrado, ya que podría presentarse estudios sobre constitucionalizaciones de alguna parte del derecho con problemas especiales a bordar, por ejemplo algunas posturas teorías deben justificar porque prefieren o suponen una constitucionalización del ordenamiento jurídico o una constitucionalización de las fuentes del derecho, o porque sólo abordan la constitucionalización de derechos o la constitucionalización de contratos, exigiendo no sólo revelar el concepto de Constitución y de Derecho adoptado, sino la razón de la parcela escogida o el concepto de la categoría del derecho asumida.

Constitucionalización y activismo.Pueden plantearse distintas clases de construcción práctica de la constitucionalización del derecho, las cuales dependen, del sujeto, activista o conductor principal del proceso de constitucionalización, el cual a su vez está limitado según la autopista constitucional vigente y los vehículos seleccionados o disponibles. Por otra parte, para un estudio de la constitucionalización del derecho como razón práctica, involucra necesariamente diferentes situaciones y actores, en las que se desarrolla y se conduce el "proceso" en la práctica, derivándose de allí distintas clases de constitucionalización. Se presenta como un actor indispensable en este "proceso" en especial para unas posturas jurídicas que pretenden eliminar rasgos políticos, a la Corte Constitucional, sin embargo, sin salirse de la distinción con los "procesos" de constitucionalización política, se puede

$9 \quad$ Al respecto hay diferentes posturas, por ejemplo para Uprimny, la Constitución colombiana al ser también abierta, no constitucionalizó un modelo económico determinado o rígido, y en cambio admite que se activen procesos de constitucionalización de modelos económicos diversos, otorgando una amplia libertad de reforma al Legislador y un margen amplio de actuación al Ejecutivo, dentro de ciertos límites constitucionales, axiológicos y normativos, que reconocen principios y derechos, así como formas de constitucionalización. En ese sentido se puede tener la Constitución como un Carta de triunfo contra la mayoría del parlamento y como una Carta abierta a los nuevos desafíos de desarrollo, al respecto Ver Memorias del Conservatorio "Diálogo entre abogados y economistas sobre la Constitución en el aspecto económico" (2007). 
plantear como actor principal al ejecutivo. En sede judicial, la Corte al interpretar la Constitución construye procesos de constitucionalización del derecho, desde el ejecutivo, el Presidente (desde un enfoque político-jurídico) al presentar reformas constitucionales introduce proceso de constitucionalización de políticas. La primera depende de que la Corte ejerza un papel activista, y la segunda de que prexista un hiperpresidencialismo ${ }^{10}$.

\title{
1.3. El proceso de constitucionalizacion fuerte del ejecutivo
}

\author{
“...posiciones extremas, y siempre recurrentes... no son más que un momento \\ normal en el cambio alternado de los estudios... la tarea... puede consistir en \\ procurar que en la reacción contra \\ El pasado no se pierda aquello que era válido, \\ digno de ser conservado, evitar que por odio a cualquier exceso se quiera \\ recomenzar todo desde el principio, y por amor a lo nuevo por lo nuevo, se \\ presente como descubrimiento...una exhumación..."
}

Bobbio

Tal vez no sea descabellado decir que los primeros promotores de constitucionalizaciones no fueron en principio juristas, que su defensa y origen parece ser de antes de la guerra, y que precisamente su práctica al desbordarse, obligó a introducir postulados para posibilitar someter al constitucionalizador a un juicio donde cualquier ciudadano pudiera exigirle cumplidamente justificaciones de su comportamiento ante el Derecho (García, 1983).

Esta es una idea vieja especialmente de un modo de constitucionalismo, pero sirve para justificar que en la actualidad la razón principal para que muchos en Europa y algunos en América Latina teman a los procesos de constitucionalización e intenten medirlos dentro de una categoría jurídica, es porque persisten márgenes de discrecionalidad amplios, validose incluso legítimos, en las ramas del poder que pueden llevarnos a cualquier camino.

Los estudios sobre cambios estructurales en momentos determinados para lograr ejercicios de sustitución de la Constitución son fácilmente rastreables, sin embargo no son abordados como desarrollo de una idea de constitucionalización, o por lo menos desde una perspectiva jurídica y aislada principalmente de los intereses de los

10 Este término se rastrea en sus orígenes en América Latina, a las interpretaciones dadas a lo reseñado en 1968 por Samuel Huntington en El orden político en las sociedades de cambio, allí habría consignado que lo más importante para un país en vías de desarrollo no es su forma de gobierno sino su grado de gobierno, el cual se desarrolla en principio fortaleciendo la figura presidencial más que la figura difícil en estos Estados de la deliberación democrática. Ya como diseño de un "sistema neopresidencial" es más correcto situar el hiperpresidencialismo influenciado por el desarrollo del régimen político de Stalin en la Unión Soviética. 
estudios científico-políticos. La mayoría de los escritos los han intentado categorizar desde el constitucionalismo ideológico historicista, describiendo tres de sus momentos cumbre, el individualismo, estatalismo, y el legicentrismo o el formalismo interpretativo, pertenecientes a deseos e intereses de cada época.

En esta nueva época de transformación jurídica, muy reciente por cierto, lograr su cientificidad depende, de la manera de concebir la función de los que ejercen los poderes, de reconstruir sus procesos de racionalización, de considerar el valor de sus decisiones, teniendo en cuenta un panorama jurídico que crece, se sostifica y sistematiza a diario y a una considerable velocidad.

Ahora bien, el poder ejecutivo en procesos de constitucionalización no es un actor secundario, pero tampoco puede desarrollarlos con las mismas estrategias, ya que en esta época, al observar la oscura experiencia del pasado, el activismo de los nuevos observadores-participantes de la política constitucional le imponen nuevas exigencias, especialmente jurídicas, lo cual le impone diseñar y desarrollar nuevas estrategias.

Es necesario, para Colombia especialmente, observar la constitucionalización con una mirada más amplia, mas general, que permita identificar sus factores o elementos esenciales, evitar la discriminación de algún actor dentro de los procesos de constitucionalización, y dar el paso hacia el estudio del poder ejecutivo como actor de procesos de constitucionalización ${ }^{11}$, previendo que pueda tener distintas posibilidades de estudio ${ }^{12}$, máxime cuando se trata de procesos de constitucionalización de políticas desbordadas ${ }^{13}$, resaltando, que de un jurista se espera un examen como una conjunción desde nociones jurídicas.

Constitucionalización, Derecho y Poder Ejecutivo, obliga a incluir una perspectiva que permita algún material para la justiciabilidad, determinar sus premisas formales y sustanciales, y describir la posibilidad de responder a determinada ideología ${ }^{14}$ dirigida

11 Mauricio García Villegas con Javier Eduardo Revelo Rebolledo, men Mayorías SIN Democracia, aborda el fenómeno desde un enfoque sociopolítico, tratando como tendencia gubernamental la "seudolegalidad", sustentado en la existencia de una cultura de desestabilización de las instituciones, que a su vez exacerba la violencia y produce una enorme ilegitimidad.

12 Por ejemplo el estudio de Vanesa Elizabeth Túñer, en Contextos de crisis e hiperpresidencialismo argentino y brasilero. La interacción Ejecutivo-Legislativo entre 1989 y 1995, Editorial Académica Española, donde recompone el liderazgo presidencial principalmente en la década de los 90 y con la implementación de las recomendaciones de reforma constitucional estructurales del Consenso de Washington, para lo cual el hiperpresidencialismo jugó un papel central.

13 El hiperpresidencialismo, la seudolegalidad, la seudopolítica, o el neopresidencialismo, no son fenómenos nuevos de estudio. En Colombia la Constitución de 1886 permitía de manera más marcada la configuración de un ejercicio desbordado del Presidente, este desequilibrio de poderes intentó mitigarse con la Constitución de 1991, especialmente con lo relacionado a su influencia en la elección de los representantes de órganos de control y magistrados de las altas Cortes.

14 Habermas aborda el tema de la constitucionalización del derecho internacional de los derechos 
a planes de largo plazo, máxime si en América Latina, y específicamente en Colombia, el ejecutivo cuenta con una Autopista constitucional y los vehículos necesarios, para conducir y darle marcha a determinado constitucionalismo, y pudiendo ejecutar tal proyecto de constitucionalización por etapas.

Para justificar un estudio del proceso de constitucionalización del ejecutivo, es necesario, en primer lugar al menos abordar la evidencia de algún nivel de hiperpresidencialismo que constituya al ejecutivo como actor constitucional relevante, en segundo lugar resaltar que tal activismo del ejecutivo parte de una noción de constitucionalización político-jurídica, o mejor aún, desde una perspectiva que aborda un hiperpresidencialismo en modo jurídico-constitucional ${ }^{15}$, acogiendo o excluyendo las distintas tipologías ${ }^{16}$, y asumiendo la descripción de las distintas formas en que puede ser presentada como un caballo de Troya de ideologías políticas.

En definitiva un proceso de constitucionalización propuesto por autoridades del Estado, obedece a un plan de gestión que incluye factores jurídicos, dada la necesidad de que se ajuste a las exigencias del ordenamiento jurídico vigente, especialmente para a tiempo hacer frente al futuro ejercicio de control constitucional judicial.

Ahora bien, un proceso de constitucionalización jurídico-político de este tipo, enfrenta ahora la identificación de la dimensión de "constitucionalización" a la que se suscribe, es decir, un plan de constitucionalización jurídica debe tener en cuenta si pretende o involucra a través de los actos de reforma, la constitucionalización del derecho, la constitucionalización del ordenamiento jurídico, la constitucionalización de derechos, la constitucionalización de una política, entre otros frentes. Esta razonabilidad invierte el orden de los factores en los que tradicionalmente se ha abordado la constitucionalización, ya que debe pasar por resolver las cuestiones sobre que se pretende constitucionalizar, la diferencia con la constitucionalización manejada por los Tribunales, es que esta se programa, se proyecta y se pone en marcha. En un Estado hiperpresidencialista prexiste la posibilidad de que el Presidente de la República de turno, luzca como principal conductor y activista de un proceso de constitucionalización, dada la apertura constitucional de acción permitida, contrario a la tesis que sostiene que en sede judicial es un activismo no reglado, no aplica la

humanos desde una perspectiva política internacional europea. La mayoría de teorías abordan la constitucionalización del derecho, como se puede constatar en el abultado número de publicaciones en cuyo título aparecen conjuntamente dichas nociones, teniendo al derecho desde las categorías que desprecian el aspecto político, o teniendo a la constitucionalización como un factor dentro del actual cambio de paradigma que renovó y mejoro la práctica del Derecho.

15 Podrían estudiarse una reconstrucción diacrónica del constitucionalismo político, o una comparación entre el constitucionalismo político dictatorial frente al constitucionalismo político actual. Del mismo modo las formas de ejecución de algún constitucionalismo político desde una constitucionalización política, como lo asume Habermas (2012) en su estudio reciente constitucionalización del derecho internacional para una Constitución Europea.

16 Por ejemplo, se excluyen las tesis sobre constitucionalización jurídica que involucran como actor protagónico a la Corte Constitucional cuando interpreta la Constitución, que producen constitucionalización de derechos, o ejercicio de control político desde lo jurídico, o incuso función de poder constituyente. Al respecto ver De Franco (2012). 
apología a "Giges" (Platón, 1997) que podría activar con alguna facilidad alguna clase de proceso de constitucionalización, que desde un enfoque jurídico-político, es legítimoy valido.

Hasta aquí se intentaba insistir en este fenómeno el cual no es exclusivo de Colombia, por ejemplo, Norberto Bobbio (2004) lo describe como un proceso graduado y sistemático en la década de los años treinta en Italia, Ferrajoli (2004)lo enuncia como crisis de la legalidad que incluye ausencia o ineficacia de los controles (la denomina fenomenología de la ilegalidad del poder) ${ }^{17}$, Luhmann representa la idea como crisis regulativa del derecho debida a la elevada "complejidad" de las sociedades contemporáneas. Se seguirá insistiendo en la tesis del activismo constitucionalizador del ejecutivo, partiendo de un estudio que relata las principales características del hiperpresidencialismo antes mencionado.

Preguntas a partir de las reflexiones de Carlos Bernal Pulido (2007). Según el profesor Carlos, la práctica de un hiperpresidencialismo fuerte y desbordado ha sido recurrente en todo el continente de América, especialmente en los países latinos, incluso desde el inicio de su lucha por la independencia y soberanía. En este contexto cabría preguntarse si ¿el fenómeno del hiperpresidencialismo puede ser estudiado desde los cánones de procesos de constitucionalización? y en ese sentido si ¿es válido categorizar procesos de constitucionalización dirigidos por el Poder Ejecutivo? y si es posible que ¿los procesos de constitucionalización responden a una ideología e inician su concepción sin Constitución escrita?

A pesar de poder abordar el fenómeno de manera global o general, el profesor Bernal (2007) contribuye aportando material para un constitucionalismo latinoamericano. Señala en primer lugar que el hiperpresidencialismo, es un fenómeno que fue acogido y preferido en varios países de América Latina, lo cual marca la primera y singular distinción con lo acontecido en Europa. Según esta tesis, esto debe explicitar de distintas maneras, la posición frente a Cortes activistas, es decir, si se acepta con mayor vehemencia en América Latina por ejemplo, Cortes Constitucionales protagonistas del papel de controlar los Actos Legislativos, el cual en el caso colombiano, permite construcciones doctrinal es sobre la prohibición de sustitución de la Constitución.

Podría plantearse desde el aporte del profesor Carlos, que el fenómeno del hiperpresidencialismo latinoamericano se caracteriza principalmente por colocar en la figura Presidencial las aspiraciones más ambiciosas del constitucionalismo, para lo cual le otorga un sitio jurídico y constitucional de privilegio, permitiendo incluso su ejercicio como actor y activista de procesos de constitucionalización, a pesar de que prexista el riesgo de alterar el ejercicio de control político del poder legislativo, ya que dicho déficit puede ser suplido por un activismo acentuado por parte de la

17 Tal fenomenología podría intentar caracterizarse desde la óptica de un "Estado Paralelo", que incluiría un sistema de corrupción que envuelve la política, la economía, la administración pública, las finanzas, entre otros. 
jurisdicción, sobre todo de la jurisdicción constitucional.

Ahora bien, tal hiperpresidencialismo pone la mirada en la Corte Constitucional misma, ya su papel de controlador de lo político desde lo jurídico, y esto a su vez, pone al poder ejecutivo a buscar caminos jurídicos para sus políticas públicas, esto dado a que su interlocutor, es el discurso jurídico constitucional, que en últimas es quien ahora da el respaldo y configura la legitimidad de la acción política estatal. En síntesis, es diferente un proceso de constitucionalización en Dinamarca que en Cundinamarca, el orden de los factores ha sido alterado, la excelentísima y profunda reflexión de Bernal (2007), así lo deja degustar.

Así las cosas, la prominencia del hiperpresidencialismo, el déficit de control parlamentario y las batallas ganadas en lo jurídico ${ }^{18}$, asientan un nuevo constitucionalismo, o mejor, el constitucionalismo político del presidente de turno, lo cual evoluciona desde los caminos de la constitucionalización.

Es necesario estudiar los casos en detalle de "reformas" constitucionales, que permitan reforzar, desnudar y revelar, los indicios de lo anteriormente señalado, que como lo que denuncia Bernal (2007), también refleja las faltas del control de la Corte, las cuales a pesar de que en principio respondían a un control jurídico objetivo, se han transformado en un control con claros tintes políticos, por lo tanto, la esperanza de un control al hiperpresidencialismo constituyente, no es sino una falacia simbólica, que permite decisiones jurídicas constitucionales desde una élite hermenéutica epistemológica, cada día con mayor respaldo, no únicamente en la opinión pública sino también en ciertos sectores de la academia, como se dejó ver con el apoyo a la presentación de objeciones presidenciales ${ }^{19}$, que evito que la Corte Constitucional evaluara la constitucionalidad de una reforma constitucional, y anuló

18 El oficio judicial, sin ser el tema central en este escrito, se aborda indirectamente, partiendo del supuesto de que en el campo del control a los poderes públicos, es discrecional, así se deja ver de las do posturas extremas derivadas de la interpretación de la cláusula bicondicional constitucional que gobierna la función constitucional de control, el numeral 1 del Artículo 241 constitucional dice algo como, la Corte Constitucional ejercerá control jurídico constitucional a las reformas deliberadas en el parlamento, si y solo si, se trata de vicios formales en su formación en el Congreso. Es claro que dicho oficio judicial en ocasiones ha sido interpretado así, y en otros casos de manera expansiva, son pocos los casos donde la Corte examina materialmente las reformas, sin embargo son una puerta importante, pero con elementos de discrecionalidad. Al respecto Josep Aguiló (2008), en Sobre Derecho y argumentación, reflexiona sobre la aplicación del Derecho (con mayúscula) y la construcción del razonamiento jurídico, en un "mundo tremendamente cambiante y complejo", especialmente en los casos de control de los actos de reforma del parlamento, en donde la Justicia como valor, está "indisolublemente unido a los conceptos de democracia y de Estado", e igualmente a las ideas políticas de turno, por tanto el oficio judicial, especialmente el constitucional, debe estar embestido de garantías para la acción con independencia, imparcialidad y racionalidad, especialmente frente a la actuación de los poderes públicos.

19 Objeciones Presidenciales al proyecto de Acto Legislativo número 143 de 2011 Cámara, 07 de 2011 Senado -acumulado con los proyectos de acto legislativo número 9 de 2011 Senado, 11 de 2011 Senado, 12 de 2011 Senado y 13 de 2011 Senado- "por medio del cual se reforman Artículos de la constitución política con relación a la administración de justicia y se dictan otras disposiciones. 
el ejercicio al derecho fundamental de la acción de inconstitucionalidad ${ }^{20}$, por tanto, una decisión sobre el fondo jurídico de su inconstitucionalidad.

Ahora tan sólo se describirán algunos puntos de vista sobre la reforma más emblemática del constitucionalismo colombiano, que cuestiona todo el proceso de reforma constitucional, desde la actividad en el parlamento, hasta el control de la Corte Constitucional, cuyo estudio pretende ayudar a demostrar la existencia de un proceso de constitucionalización fuera de los cánones establecidos o bien por la exaltación al Estado Constitucional Democrático de Derecho, o a la preferencia de unas garantías individuales frente al control material y ético del ejecutivo, con el propósito de servir como material para una discusión o un planteamiento problemático futuro, en una tesis de investigación al respecto.

\title{
2. DOCTRINA DE LA SUSTITUCIÓN DÉBIL DE LA CORTE CONSTITUCIONAL LA CORRUPCIÓN COMO FUENTE DE DERECHO
}

\begin{abstract}
"Lo que está en juego, en definitiva, son los derechos de los ciudadanos y las ciudadanas, cuyo mayor garante es un sistema judicial que actúe con independencia, imparcialidad y racionalidad, especialmente frente a la actuación de los poderes públicos"
\end{abstract}

Aguiló

Controlar al ejecutivo desde sede judicial cuando se trata de situaciones de anormalidad, no es nuevo ${ }^{21}$, podría decirse que sus bases son particulares en cada ordenamiento en particular. La doctrina colombiana sobre el control constitucional a los actos legislativos que intentan reformar la Constitución y que involucran estudios de competencia del legislativo, tiene como origen momentos lejanos, que datan incluso de registros anteriores a la Constitución de $1991^{22}$, su evolución ya ha sido estudiada, sin embargo si se trata de realizar los enlaces con la hiperactividad reformista del ejecutivo existen algunos vacíos, en especial frente al juicio al control

20 Desde su creación en 1991, la Corte Constitucional ha producido una jurisprudencia abundante y novedosa para el contexto colombiano. Tan sólo entre 1992 y 2002, la Corte decidió casi 3000 acciones públicas de inconstitucionalidad; Ver cuadro comparativo del trabajo de las Cortes Constitucionales de Latinoamericana de la Universidad Carlos III de Madrid www.uc3m.es

21 Una Sentencia de significación universal por ser la que inaugura la técnica del control de constitucionalidad de las leyes, la produjo en 1803 el Tribunal Estadounidense en el caso Marbury v. Madison. Un enfoque incluso crítico del detalle de esta famosa Sentencia lo realiza Eduardo García de Enterría (2009) en Una reflexión complementaria. sobre la doctrina norteamericana de la deferencia judicial hacia el ejecutivo, Editorial Aranzadi, analizando la afirmación en la Sentencia sobre la "extravagancia" de pretender un control judicial del Ejecutivo, al igual que el estudio de la Sentencia Kedall de 1838 que condena por primera vez al Ejecutivo.

22 Por ejemplo, por citar un referente especial e importante, la Corte Suprema de Justicia en 1978 desde la Sala Plena, sentó como precedente en la Sentencia de mayo 5 de 1978 teniendo como M.P. al Dr. José María Velasco Guerrero, que la Corte es competente para conocer de las demandas contra reformas de la Constitución a través de actos legislativos. Ver Gaceta Judicial, número 2397/78. p. 99. 
constitucional que declaro exequible la introducción de la relección en Colombia, por lo menos respecto a la argumentación democrática post 2008.

La Corte Constitucional de Colombia, no permitió desarrollar alegatos específicos sobre la estipulación en la Carta Constitucional de una disposición normativa que permite la relección presidencial, que después del 2008 según hechos verificados, vinculó compra de votos y delitos en su trámite, con Sentencia condenatorias al respecto. La Corte Constitucional de Colombia rechazó pronunciarse y examinar ciertos hechos que se presentaron como "antecedente contextual concerniente a la historia de la estipulación de la relección en la Constitución”, por considerar que no le está en los tiempos para pronunciarse respecto a hechos alegados, luego una acción del derecho fundamental a la acción de constitucionalidad no es posible ser estudiada.

A pesar de que el tema involucra el derecho a la verdad, a la información y el debido proceso, además del principio democrático, la inadmisión del estudio de control de constitucional, no permitió una distinción o categorización de cada uno de los problemas, ni la valoración conjunta de todas las circunstancias fácticas.En definitiva, el contexto no ha sido materia del control de constitucionalidad a pesar de que guarda relación con los hechos de la aprobación del Acto Legislativo condenados por la Corte Suprema de Justicia.

Cabe entonces preguntarse, si ¿se contraviene el principio democrático al permitir que un número reducido de jueces nieguen el estudio de la constitucionalidad formal de un Acto Legislativo, a pesar de que tal texto fue conformado en base a un delito que deslegitimo la deliberación representativa? Esta pregunta se comparta o no su formulación, está presente en el constitucionalismo colombiano, ya que representa es caso de la introducción a la Constitución de una reforma a la relección presidencial, el cual tal vez refleja con mayor claridad, el marcado hiperpresidencialismo y caudillismo parlamentario, -para otros puede ser la "reforma a la justicia" (2012) ${ }^{23}$ - y la discrecionalidad que puede practicar en ejercicio del control constitucional judicial material, la Corte Constitucional.

Ahora bien, se describirán las huellas de esta afirmación, para complementar el estudio jurídico al test de sustitución al Acto Legislativo ${ }^{24}$, haciendo relevancia a

23 En este escrito se reflexiona el caso de la "reforma a la justicia" que muestra la iniciación del ejecutivo como guardián material de las reformas. También se examina la acción de inconstitucionalidad como derecho fundamental y herramienta de contrapeso al descontrol de reforma, al igual que se describe un rastreo preliminar de la teoría que asume la problemática de las tensiones entre el principio democrático y la supremacía de la Constitución.

24 La Corte Constitucional en las Sentencias C-1040 y C-1041 se pronunció de manera específica sobre el trámite legislativo del Acto Legislativo 2 de 2004 en relación con los distintos cargos que se habían formulado en su contra. Adicionalmente, en relación dicho acto legislativo, la Corte expidió las Sentencias C-1042, C-1043, C-1044, C-1045, C-1046, C-1047, C-1048, C-1049, C-1050, C-1051, C-1052, C-1053, C-1054, C-1055, C-1056 y C1057 de 2005, C-034, C-174 y C-278 de 2006, abordando en la mayoría de ellas el fenómeno de la constitucionalización. 
los hechos relacionados ${ }^{25}$ con la Sentencia No.172 de junio 26 de 2008 de la Sala de Casación Penal de la Corte Suprema de Justicia, que se emitió dentro del proceso adelantado contra Yidis Medina Padilla, quien en su calidad de ex Representante a la Cámara aceptó cargos por el delito de cohecho propio ${ }^{26}$, habiéndose divulgado previamente su confesión ${ }^{27}$ de que había cometido el delito al votar la reforma constitucional que permitía en el 2005 la reelección presidencial, cuya reforma explícitamente permitió que el entonces presidente Álvaro Uribe, elegido en 2002 por cuatro años, pudiera renovar su mandato en 2006.

La Sala de Casación Penal de la Corte Suprema de Justicia por sólo tener competencia para juzgar los delitos cometidos por los congresistas, y carecer de ella para investigar los votos o el sentido de las opiniones que los legisladores emitan en el ejercicio de sus funciones, remitió a la Corte Constitucional el estudio de constitucionalidad del Acto Legislativo a favor del proyecto de reelección presidencial, por estar condicionado por actos corruptos previos al debate donde se consideró la reelección, por razón a que: i) la corrupción en el ejercicio de la función pública no puede ser fuente del derecho, ii) que la contratación pública ejecutada con desconocimiento de las reglas que la regulan conlleva severas sanciones y iii) asumiendo que la lucha del Estado contra la impunidad tiene relevancia constitucional y es incompatible con la filosofía del Estado social y democrático de derecho que un acto legislativo desviado, de connotaciones delictivas tenga vigencia y ejecutividad.

La Corte a través del Auto 156 de 2008, dio respuesta a la remisión de la Corte Suprema de Justicia, irguiendo como principal argumento que ha perdido la competencia para emitir un nuevo pronunciamiento sobre el Acto Legislativo 02 de 2004, posición criticada por el Magistrado Jaime Araújo desde su salvamento de voto

25 Uno de estos hechos es por ejemplo que el día 1 de junio de 2004, según la Sentencia de la Corte Suprema de Justicia, 18 de los 35 congresistas integrantes de la Comisión Primera Constitucional de la Cámara, entre ellos la ex Representante Yidis Medina Padilla, se reunieron en silencio por temor a represalias del hiperpresidencialismo vigente, en la casa de la también Representante Clara Isabel Pinillos Abozaglo, para acordar y firmar una proposición sustitutiva para el archivo del proyecto de Acto Legislativo que pretendía la relección, la cual tenían que presentar al día siguiente en la sesión de la Comisión Primera de la Cámara. Al día siguiente (2 de junio de 2004), la ex Representante a la Cámara, según la Sentencia de la Corte Suprema de Justicia, antes de la discusión del proyecto de reforma constitucional para introducir la relección presidencial en la Constitución, había sido citada al Palacio de Nariño.

26 Según la Secretaría General de la Cámara de Representantes, la ex Representante a la Cámara Yidis Medina Padilla se desempeñó como congresista entre el 1 de abril y el 30 de junio de 2004, para cubrir la licencia del titular de la curul Iván Díaz Mateus, elegido para ese cargo por el Departamento de Santander del Partido Conservador Colombiano. El delito de cohecho se ejecutó en la votación del Proyecto de Reforma Constitucional No. 267/04 Cámara y 012/04 Senado, mediante el cual se pretendía reformar el Artículo 197 de la Carta Política colombiana, para incluir la figura de la relección presidencial, dentro de la Comisión Primera, célula legislativa de la Cámara a la que le corresponde la discusión y votación de las reformas a la Constitución Política colombiana.

27 Según la Sentencia de la Corte Suprema de Justicia, 4 años después de aprobada la reforma constitucional de relección presidencial, Yidis Medina el 20 de abril de 2008 autorizó se emitiera una entrevista que había sido gravada desde agosto 8 de 2004 concedida al periodista Daniel Coronell para que se conociera el delito a la opinión público, al sentir que su vida estaba en peligro. 
al Auto. Es importante recordar como lo hizo el Magistrado Rentería, que en esta Sentencia la Sala Penal de la Corte Suprema de Justicia dejo claro que en el proceso legislativo de aprobación del Acto Legislativo No. 02 del 2004 en el Congreso la actuación y el voto de la entonces congresista Yidis Medina fue definitivo y determinante para la aprobación del Acto Legislativo de la reelección, se comprobó que existió una maniobra para no aceptar el impedimento, ya que "sin el voto de Yidis Medina no habría sido posible la reelección”, por tanto existe un vínculo directo, inmediato y consustancial entre este voto y la aprobación de la reelección presidencial, constatándose las circunstancias de factum y de iuris que sirvieron para comprobar que la aprobación de la reforma constitucional fue expresión de una clara desviación de poder ${ }^{28}$, convalidación de un delito y de la corrupción.

Sin embargo, dicha constitucionalización no puede sólo concebirse como un exceso del constituyente derivado o la escasez de la argumentación democrática en cabeza de la Corte Constitucional, a pesar de que afecta de manera directa la confianza en el proceso deliberativo y procedimental que desarrolla el Congreso de la República y la Corte Constitucional cuando tramita y controla una reforma constitucional, ya que quien ejerce el activismo hiperfuncional que afecta el principio democrático y la supremacía de la Constitución es del ejecutivo, luego el examen sobre si las razones del ¿qué?, ¿cómo? y ¿por qué? de las constitucionalizaciones, deben incluir el activismo del ejecutivo, junto con sus obligaciones convencionales y constitucionales, por tanto un juicio sobre si deben mantenerse o por el contrario sustraerse, normas irregulares de la Constitución, debe incluir los debates en torno a la constitucionalización de actos de corrupción, y determinar los estándares que enfrentan la existencia un activismo de constitucionalización desbordado, para lo cual es necesario darles cabida dentro de la formulación de los modos, tipos y dimensiones de la constitucionalización.

Sin embargo, también es necesario que la infracción a la democracia sea justiciable, y ante la omisión de la Corte Constitucional, debe haber una apertura a la justicia internacional protectora de la democracia, que termina generando desconfianza sobre la justiciabilidad de las reformas, sobre la existencia de límites a la democracia procedimental. Colombia pasa a ser ejemplo de lo que no se debe hacer en materia constitucional y se aplique el principio del derecho romano fraus omnia corrumpit, en este caso, todos los actos jurídicos en los que haya mediado fraude en su formación, pueden ser declarados nulos.

28 La ex Representante Yidis Medina, para darle relevancia mediática a la noticia de fraude del Acto Legislativo que permitió la introducción a la Constitución Política de la Relección Presidencial, un mes después de haber sido condenada, posó desnuda para la Revista SoHo desde la cárcel El Buen Pastor donde estaba restringida en su libertad, acompañada de una entrevista concedida a la periodista Salud Hernández-Mora. 


\title{
3. DOCTRINA INTERAMERICANA FORTÍSIMA
}

\author{
"El centro de gravedad del orden jurídico se ha desplazado... pero... \\ ¿La constitucionalización del derecho podrá imponerse sobre un proceso de \\ integración comunitaria?...
}

¿Se puede pensar que la constitucionalización puede progresar más?’

Favoreau

Frente a la escasez en la argumentación democrática y los excesos de la democracia procedimental en el actual imperio del hiperpresidencialismo constitucional, se fortalece en América Latina dentro del actual proceso de transformación jurídica constitucional, el control convencional, en algunos países con mayor velocidad y entusiasmo como es el caso de México, Costa rica, Colombia y Argentina, y en otros con cierto escepticismo y resistencia como Brasil, México y Chile. Esta transformación se debe a múltiples factores, pero son de resaltar principalmente el giro teórico dado por la apertura constitucional a los derechos humanos, y el nuevo rol reflejado de la actividad de la Corte Interamericana de Derechos Humanos ${ }^{29}$. Cabe entonces preguntarnos si ¿la justicia interamericana puede invalidar resoluciones administrativas y judiciales internas, cuando se trata de constitucionalizaciones inconvencionales? y si ¿existen casos en la Corte Interamericana de control a lo resulto por el poder de reforma constitucional y su respectivo control constitucional?

Debe decirse, en primer lugar, que existe una puerta constitucional que valida el preguntarse si un proceso de constitucionalización del ejecutivo pueda ser sometido a un ejercicio de control de convencionalidad en sede del máximo tribunal garante de la Convención Americana de Derechos Humanos, la cual se sustenta la interpretación de que la actividad estatal no sólo está sometida a la Constitución sino a los compromisos convencionales de garantizar y promover los derechos humanos, lo cual obliga a las autoridades a justificarse dentro de un Estado convencional armonizando el derecho ${ }^{30}$.

29 La Historia de la Corte IDH y de la CADH es más antigua que la de la Corte Constitucional colombiana y la Constitución de 1991, sin embargo su activismo sólo empieza a producir cierta velocidad recientemente. La Corte IDH surge desde la CADH de 1969, después de un proceso largo de acuerdos internacionales que datan del periodo de sesiones de la OEA de 1949. La CADH que crea la Corte IDH, soló entró en vigor hasta el 18 de julio de 1978, al haber sido depositado el undécimo instrumento de ratificación por un Estado Miembro de la OEA, y sólo hasta 1980 la OEA aprobó el Estatuto de la Corte. Su primera Sentencia de Fondo se produce en 1989 Caso Velázquez Rodríguez Vs Honduras, y le siguen casos de estudio de masacres donde se involucra la responsabilidad internacional de los Estados. Falla por primera vez contra Colombia en 1994 en el Caso Caballero Delgado y Santana.

30 El principio pro persona explícitamente se encuentra en el Artículo 29 de la CADH, que ordena interpretar el deber de garantía de los derechos humanos de la manera más favorable a la persona, aplicando el régimen vigente donde estén mejor desarrollados, el cual prohíbe dejar de aplicar la 
En segundo lugar, que en la reciente década se puede ver a una Corte IDH que asume el rol de Corte Latinoamericana, especialmente porque ha dejado de asumir sólo casos de masacres, dado a la sostificación del sistema por parte de sus actores, teniendo entonces que abordar casos de especial complejidad, involucrando en su dinámica de control estatal a todas las autoridades estatales, incluyendo incluso la de los jueces. Ahora bien, solo presentare dos casos emblemáticos que evidencian dicha tendencia.

El primero de ellos es la orden de la Corte Interamericana al Estado de Chile de modificar su ordenamiento jurídico interno, con el fin de suprimir de él la censura previa, y se adecuen a lo contemplado en los Artículos1.1, 2 y 13 de la Convención que garantizan el respeto y el goce del derecho a la libertad de pensamiento y de expresión, esto implicó que el Estado chileno modificará el Artículo 19 (12) de su Constitución de 1980 que disponía que: “...la ley establecerá un sistema de censura para la exhibición y publicidad de la producción cinematográfica y fijará las normas generales que regirán la expresión pública de otras actividades artísticas"31. Está eliminación de la censura cinematográfica, permitió la exhibición de la película "La Última Tentación de Cristo" 32 , una película de ciencia ficción, que narra la vida de Jesús, cambiando sustancialmente el momento de la crucifixión. Concluimos con este caso, que la Corte Interamericana de Derechos Humanos tiene la facultad de ordenar a un Estado que cambie hasta sus preceptos constitucionales para que estos se adecuen a lo pactado en un Tratado Internacional.

Un segundo caso es el de Radilla Pacheco Vs México, del 23 de septiembre de 2009, en donde indicó en especificó que los jueces, como parte del aparato del Estado, están sometidos a la Convención Americana, por tanto deben someterse a ella, por tanto deben ejercer control de constitucionalidad ex officio entre las normas internas y la Convención, indicando entonces que el Artículo 13 de la Constitución Política de los Estados Unidos Mexicanos solo puede entenderse y aplicarse, sino en relación

Constitución si esta es más generosa que la CADH y dejar de aplicar un tratado con el argumento de que la constitución es superior, esto no quiere decir que se reconoce superioridad o jerarquía, sino que en el caso concreto se aplica la más favorable. Un ejemplo se puede ver en la SentenciaC-376 de 2010 del M.P. Dr. Luis Ernesto Vargas Silva, que declaró la EXEQUIBILIDAD condicionada del Artículo 183 de la Ley 115 de 1994, la cual interpreta el Artículo 67 de la Constitución y el Pacto o Protocolo de San Salvador en materia de educación, decidiendo la Corte que la norma más favorable era la del instrumento internacional.

31 En el Caso Durand y Ugarte, del 16 de agosto de 2000, también se estableció que el Artículo 2 de la Convención, incluye la obligación de adoptar medidas para suprimir las normas de cualquier naturaleza que impliquen una violación a las garantías previstas en la Convención.

32 Caso La Última Tentación de Cristo (Olmedo Bustos y otros) vs. Chile, Sentencia de 5 de febrero de 2001(Fondo, Reparaciones y Costas). La ficción propone una tentación no prevista en los evangelios según la cual, Jesús al momento de su crucifixión es tentado con una visión de cómo sería su vida después de que un supuesto ángel en nombre de Dios le lleva como mensaje que no es el Mesías, que no debe morir, y que lo bajará de la cruz para que viva con una esposa http://www.youtube.com/ watch?v=A5X5eD6TJeA 
con la Convención y la jurisprudencia que ha emitido la Corte Interamericana al respecto $^{33}$.

En tercer lugar, sin ser el último único caso, recientemente la Corte Interamericana ordeno al Estado de Costa Rica, en un plazo de seis meses y un año, modificar lo establecido mediante Sentencia de la Corte Constitucional, la cual indicó que al decidir sobre la inconstitucionalidad del Decreto que regulaba la Fecudación In Vitro, prohibió indirectamente su práctica, a condicionar el uso de su técnica futura, a procedimientos que garanticen la protección absoluta de la vida del embrión, a través de la prohibición de desechos de embriones. La Sentencia al ser fuente de interpretación desde su promulgación puede ser considerada una expansión de la Constitución costarricense, por tanto la orden de la Corte del mismo modo afecta también las interpretaciones constitucionales del máximo guardián de la Constitución local ${ }^{34}$.

Los anteriores casos muestran una marcado y veloz evolución del control de convencionalidad a reformas e interpretaciones constitucionales, lo cual podría evolucionar como segunda instancia de control a los excesos en las reformas constitucionales del parlamento y como primera instancia a la escasez en el ejercicio de control material de la Corte Constitucional.

\title{
4. REFLEXIÓN FINAL: HACIA UN CONTROL DE CONVENCIONALIDAD
}

\begin{abstract}
"Antes de considerar qué acciones son buenas o malas, justas o injustas, lo apropiado es considerar primero lo que se quiere decir con, y lo que no se quiere decir y lo que se incluye en y lo que no se incluye en, la expresión hacer una acción o hacer algo"
\end{abstract}

Austin

Frente a la sobreconstitucionalización como ejercicio del hiperpresidencialismo negativo, los excesos como constituyente derivado de la democracia deliberativa del parlamento y la escasez en la argumentación democrática de la Corte Constitucional en ejercicio de control a las reformas, surge el control convencional como propuesta armónica de control, el cual exige un estudio sobre los criterios del hiperpresidencialismo denunciado, una acepción del proceso de constitucionalización desbordado del ejecutivo, las debidas verificaciones de vulneración a la tutela judicial al derecho fundamental de la acción de inconstitucionalidad y los debidos juicios a

33 En este caso los representantes habían solicitado a la Corte Interamericana que ordenara al Estado de México realizar una reforma constitucional al Artículo 13 de la Constitución de los Estados Unidos Mexicanos, que regula el "fuero de guerra", en razón a las múltiples interpretaciones que podría generar su ambigüedad. Un análisis al respecto ver en Caballero J. (2009).

34 Caso Artavia Murillo y otros ("Fecundación In Vitro") Vs. Costa Rica, de 28 de noviembre de 2012, (Excepciones Preliminares, Fondo, Reparaciones y Costas). 
los razonamientos de control constitucional por parte de la Corte Constitucional, por lo menos si se quiere someter a las autoridades estatales a la Convención Americana y a la jurisprudencia de la Corte Interamericana, aprovechando la maduración del sistema de protección de los DDHH y la apertura a la constitucionalización del derecho internacional de los derechos humanos, la cual se da de manera directa por disposición constitucional como es el caso mexicano, de manera mixta como lo es en Colombia, o vía interpretativa como el caso de Chile.

\section{REFERENCIAS}

Aguiló, J. (2008). Sobre Derecho y argumentación. Mallorca: Editor Lleonard Muntaner.

Palma, C. (2009). El Neoconstitucionalismo y la Normatividad del Derecho. Escritos de Derecho Constitucional y Filosofía del Derecho, Serie intermedia de teoría jurídica y filosofía del derecho (7), Bogotá: Universidad Externado

Bernal, C. (2007). La democracia como principio constitucional en América Latina, en Revista Cuestiones constitucionales (17), 21. Instituto de Investigaciones Jurídicas: Universidad Autónoma de México.

Bobbio, N. (2004). El Problema del Positivismo Jurídico (Ernesto Garzón Valdez, trad., 1965). Serie Biblioteca de Ética, Filosofía del Derecho y Política (12). México: Editorial Fontamara.

Bobbio, N. (1982). El problema de la guerra y las vías de la paz. Barcelona: Editorial Gedisa.

Caballero J. (2009). La incorporación de los tratados internacionales sobre derechos humanos en España y México. México: Porrúa.

Calderón, J.J., López, N., Rincón, E. (2005). La constitucionalización del derecho privado en Colombia: supuestos de investigación. Bogotá: Editorial Universidad del Rosario

Calderón, J.J. (2007). Constitucionalización del derecho comercial: algunas de las huellas trazadas por la jurisprudencia de la Corte Constitucional de Colombia, en Revista Universitas enero-junio, (113), 113-137. Bogotá: Universidad del Rosario.

Calderón, J.J. (2011). La constitucionalización del derecho privado. La verdadera historia del impacto constitucional en Colombia, Facultad de Jurisprudencia Universidad de los Andes, Bogotá: Editorial Temis.

Comanducci, P. (2010). Hacia una Teoría Analítica del Derecho. Ensayos escogidos. Colección EL Derecho y Justicia. Madrid: Centro de Estudios Políticos y Constitucionales.

Comanducci, P., Ahumada, M., González, D. (2009). Positivismo jurídico y neoconstitucionalismo. Coloquio Jurídico Europeo, (16). Madrid: Editorial Fundación. 
Ferrajoli, L. (2001). Derechos y garantías. La Ley del más débil. Colección estructuras y procesos, Serie Derecho. Madrid: Editorial Trotta.

Ferrajoli, L. (2004). Crisis del derecho y crisis de la razón jurídica, en Derechos y garantías. La Ley del más débil, (pp. 15-20).

Fuller, L. (1969). Anatomía del Derecho (Luis Castro, trad.). Monte Avila (Eds.), Colección Perspectiva Actual. Caracas.

García, E. (1983). La lucha contra las inmunidades del Poder en el derecho administrativo. Madrid: Civitas Ediciones.

Guerrero, F. (2012). Píldoras para salvar la constitución de 1991. Excesos de la democracia procedimental y escasez en la representación argumentativa (I Parte). Revista Iustitia (10). Bucaramanga: Universidad Santo Tomás Seccional Bucaramanga, Facultad de Derecho.

Hesse K. (2011). Escritos de derecho constitucional, Fundación Coloquio Jurídico Europeo. Madrid: Centro de Estudios Políticos y Constitucionales.

Laporta, F. (2004). Constitución: Problemas filosóficos. Madrid: Centro de Estudios Políticos y Constitucionales.

Platón. (1997). La República, 4ª ed., (José Tomás y García, trad.). Bogotá: Editorial Panamericana.

Rodríguez, J. (2009). El Gobierno Presidencialista del Estado Contemporáneo. Revista Iustitia (7), 127-141. Bucaramanga: Universidad Santo Tomás Seccional Bucaramanga, Facultad de Derecho.

Schimitt, C. (1982). Teoría de la Constitución, (F. Ayala, trad.). Madrid: Alianza Universidad Textos.

Suárez, W. (2011). Racionalización, racionalidad material y decisiones judiciales. Revista Iustitia (9), 243-261. Bucaramanga: Universidad Santo Tomás Seccional Bucaramanga, Facultad de Derecho.

Uprimni, R. (2007). Abierta pero no neutra: Constitución y Modelo Económico en Colombia (pp. 11-27), en Memorias del Conservatorio Diálogo entre abogados y economistas sobre la Constitución en el aspecto económico. Bogotá: Ministerio de Hacienda y Crédito Público.

Wheare, K. (1971). Las constituciones modernas (Fernando Morera y Angel Alandí, trad.). Barcelona: Editorial Labor S.A.

\section{ACTOS Y SENTENCIAS}

Acto Legislativo No. 02 de 2004. Por medio del cual se reforman los Artículos 127, 197 y 152 de la Constitución Política de Colombia y se dictan otras disposiciones.

Corte Constitucional; Sala Plena, Sentencia C-1040 de 2005, Magistrado Ponente Rodrigo Escobar Gil, aquí la Corte analiza las Sentencias C-551 de 2003, C-970 y C-971 de 2004 
Corte Constitucional; Sala Plena, Sentencia C-1040 de 2005, Magistrado Ponente Rodrigo Escobar Gil. Sentencias C-551 de 2003, C-970 y C-971 de 2004

Corte Constitucional; Auto 137 de 2006 de la Sentencia C-1040 de 2005 que declaró exequible el Acto No 02 de 2004 que aprobó la relección.

Corte Suprema de Justicia; Sala Plena, Sentencia No. 173 de 2008, que profiere Sentencia anticipada dentro del proceso adelantado contra Yidis Medina Padilla por aceptación de cargos por el delito de cohecho propio.

Corte Constitucional; Auto No 155 de 2008 que rechaza recurso extraordinario de revisión contra la Sentencia C-1040 de 2005, por existencia de vicios de procedimiento en la adopción del Acto Legislativo 02 del 2004 que aprobó la relección.

Corte Constitucional; Auto N ${ }^{\circ} 156$ de 2008 que contesta el mandato de la Sentencias de la Corte Suprema de Justicia No. 173 del 26 de junio de 2008.

Corte Constitucional; Salvamento de voto del Magistrado Jaime Araújo Rentería al Auto 155 de 2008, que rechazó de plano recurso extraordinario de revisión presentado contra la Sentencia C-1040 del 19 de octubre de 2005.

Corte Constitucional; Salvamento de voto del Magistrado Jaime Araújo Rentería al Auto 156 de 2008, en relación con el mandato de la Sentencia de la Corte Suprema de Justicia No.173 del 26 de junio del 2008.

Corte Interamericana de Derechos Humanos; Caso La Última Tentación de Cristo (Olmedo Bustos y otros) Vs. Chile, Sentencia de 5 de febrero de 2001 (Fondo, Reparaciones y Costas).

Corte Interamericana de Derechos Humanos; Caso Artavia Murillo y otros ("Fecundación In Vitro") Vs. Costa Rica, de 28 de noviembre de 2012, (Excepciones Preliminares, Fondo, Reparaciones y Costas).

Objeciones Presidenciales al proyecto de Acto Legislativo número 143 de 2011 Cámara, 07 de 2011 Senado -acumulado con los proyectos de Acto Legislativo Número 9 de 2011 Senado, 11 de 2011 Senado, 12 de 2011 Senado y 13 de 2011 Senado- "por medio del cual se reforman Artículos de la Constitución Política con relación a la administración de justicia y se dictan otras disposiciones. 
